Environmental Technology, Volume 28, Issue 12, 2007, Pages 1317-1324

\title{
KINETICS OF STRUVITE PRECIPITATION: EFFECT OF THE MAGNESIUM DOSE ON INDUCTION TIMES AND PRECIPITATION RATES
}

\author{
Kristell S. Le Corre ${ }^{1}$, Eugenia Valsami-Jones ${ }^{2}$, Phil Hobbs ${ }^{3}$, Simon A. Parsons ${ }^{*}$ \\ ${ }^{1}$ Centre for Water Science, Cranfield University, Cranfield MK43 OAL, UK
}

*Tel: +44 (0)1234 754841, Fax: +44 (0)1234 751671

E-mail address: s.a.parsons@cranfield.ac.uk

2 Department of Mineralogy, The Natural History Museum, Cromwell Road London, SW7 5BD,

UK

3Institute of Grassland and Environmental Research (IGER), North Wyke, Okehampton, Devon,

EX20 2SB, UK

\begin{abstract}
The presence of white deposits in specific areas of wastewater treatment plants is generally the consequence of the spontaneous formation of a mineral called struvite. Struvite forms when the levels of phosphate, ammonium and magnesium naturally available in wastewater effluents reach a minimum molar ratio 1:1:1 under specific conditions of $\mathrm{pH}$, temperature and mixing energy. Originally regarded as a phenomenon to control or eliminate, struvite has been lately identified as an alternative way of removing and recovering $\mathrm{P}$ from wastewater effluents and generating a product identified as an excellent base for the production of slow release fertilisers. Chemical and physical principles of struvite precipitation and the development of crystallisation technologies have been widely investigated. However, little interest has been given to kinetics of struvite precipitation. In the present work the kinetics of struvite formation have been investigated at both laboratory and pilot scale in synthetic solutions containing $\mathrm{Mg}^{2+}, \mathrm{NH}_{4}{ }^{+}$, and $\mathrm{PO}_{4}^{3-}$ ions in a molar ratio 1:2:2 at room temperature. These different tests have used $\mathrm{pH}$ measurements to assess the impact of water chemistry on induction times, and more precisely the influence of magnesium levels on kinetic rates. Experimental results and kinetic calculations revealed that the control of the magnesium dose initially present in solution is decisive of the speed at which struvite nucleates.
\end{abstract}

Key words: struvite, precipitation, kinetics, magnesium dose

\section{INTRODUCTION}

Phosphorus $(\mathrm{P})$ removal from wastewater effluents has become a real driver, especially since 1991 when European legislation made compulsory the removal of phosphorus from wastewater discharged in sensitive areas and imposed minimum P concentrations in wastewater effluents 
to limit problems of eutrophication [1]. As a result of this strict legislation, numbers of new $\mathrm{P}$ removal processes have been developed and include biological removal technologies (Biological Nutrient Removal (BNR), Enhanced Biological Phosphorus Removal (EBPR)), chemical precipitation by metal salts and lately crystallisation of $\mathrm{P}$ as either calcium phosphate or struvite $[2,3]$. Although the two first methods have been largely applied, the two others remain principally at an experimental stage. However the removal of phosphorus from wastewater effluents by struvite crystallisation is a promising solution as conversely to the other methods it presents the advantage of generating a fully recyclable product, the sales of which could benefit wastewater companies. Indeed, researchers have identified struvite $\left(\mathrm{MgNH}_{4} \mathrm{PO}_{4} \cdot 6 \mathrm{H}_{2} \mathrm{O}\right)$ as a slow release soil additive highly effective for foliar and soil application and as efficient as traditional mono calcium phosphates $(\mathrm{MCP})[4,5]$.

Struvite occurs spontaneously in solution when the content in $\mathrm{Mg}^{2+}, \mathrm{NH}_{4}^{+}$and $\mathrm{PO}_{4}^{3-}$ reaches a 1:1:1 molar ratio under specific conditions of $\mathrm{pH}$, temperature, mixing energy and presence of foreign ions [6]. Although conditions affecting success of $\mathrm{P}$ removal and recovery as struvite and their consequences on thermodynamics of precipitation have been widely investigated [7, 8], knowledge on kinetics of struvite precipitation, that is to say on rates at which struvite forms, is still limited [9]. Struvite crystallisation can be divided in two major steps: nucleation and crystal growth [10]. An important parameter of struvite precipitation is the time lapsed from the start of an experiment until the first particles occur, more commonly known as induction time $[11,12]$. Struvite induction time is known to depend on the nucleation process involved in struvite crystal formation and on a multitude of parameters including supersaturation levels, mixing energy and presence of foreign ions [9, 13, 14]. Controlling precisely the effects of all these parameters seems then fundamental in the success of struvite crystallisation. 
In the present work the influence of magnesium ions on kinetics of struvite crystallisation in synthetic liquors has been investigated. Initially used to estimate the magnesium impact on struvite induction time of struvite crystallisation, $\mathrm{pH}$ measurements have then been used to assess kinetics of struvite precipitation.

\section{MATERIAL AND METHODS}

\section{Laboratory scale investigations}

Struvite was precipitated from volumes of stock solutions of magnesium chloride hexahydrate $\left(\mathrm{MgCl}_{2} \cdot 6 \mathrm{H}_{2} \mathrm{O} /\right.$ Fisher Analytical Reagent Grade, UK) and ammonium dihydrogen orthophosphate $\left(\mathrm{NH}_{4} \mathrm{H}_{2} \mathrm{PO}_{4} /\right.$ Fisher Analytical Reagent Grade, UK) diluted in deionised (DI) water into $250 \mathrm{ml}$ flasks so that the final concentration of $\mathrm{Mg}$ after mixing ranged from $1.2 \mathrm{mM}$ to $3.5 \mathrm{mM}$; the molar ratio Mg: N:P always equalled 1:2:2. Prior to mixing, the diluted solutions were adjusted to $\mathrm{pH}$ 9, by addition of sodium hydroxide $(\mathrm{NaOH} 0.01 \mathrm{~N}$ and $2 \mathrm{~N} /$ Fisher Analytical Reagent Grade, UK). The two solutions were then simultaneously mixed together in a $600 \mathrm{~mL}$ beaker, and the $\mathrm{pH}$ was measured periodically over 25 minutes. At the end of each test, the precipitate was filtered through $0.2 \mu \mathrm{m}$ pore size Whatman membranes (Fisher scientific, UK) and dried at room temperature. The recovered product was characterised via XRD (Powder X-ray Diffractometer D5005, Siemens, Germany) and SEM (Scanning Electron Microscope XL 30 SFEG, Philips, The Netherlands).

Pilot scale investigations 
A pilot scale reactor has been designed and developed at Cranfield University (Figure 1) to study struvite crystallisation on both synthetic and real liquors.

The process was composed of a 101 reactor with three side sampling ports and a drain valve. A peristaltic pump simultaneously injected solutions of ammonium dihydrogen orthophosphate $\left(\mathrm{NH}_{4} \mathrm{H}_{2} \mathrm{PO}_{4}\right.$ / Fisher Analytical Reagent Grade) and magnesium chloride hexahydrate $\left(\mathrm{MgCl}_{2} \cdot 6 \mathrm{H}_{2} \mathrm{O} /\right.$ Fisher analytical Reagent Grade) prepared by the dissolution of the corresponding solid compounds in deionised (DI) water.

Prior to mixing in the reactor, each solution was adjusted to $\mathrm{pH} 9$ with sodium hydroxide $(\mathrm{NaOH} 2 \mathrm{~N} /$ Fisher analytical reagent grade) in stirred buckets. Both solutions were transferred in the reactor up to $9 \mathrm{~L}$ so that the final molar ratio $\mathrm{Mg}: \mathrm{N}: \mathrm{P}$ always equalled 1:2:2. A pH probe introduced in the reacting zone controlled the $\mathrm{pH}$ during the crystallisation process. The $\mathrm{pH}$ was recorded in the column shaped zone of the reactor every minute, over 1 hour of experiments.

An upward air-flow and a liquid recirculation were used and adjusted (10 to $51 \mathrm{~min}^{-1}$ for air, and 1.5 to $1.351 \mathrm{~min}^{-1}$ for liquid) to ensure the mixing and growth of the particles formed so that they were kept in suspension during the experiment. Struvite crystal harvesting was achieved through a drain valve situated at the bottom of the reactor. All standard experiments were conducted at room temperature over 60 minutes and repeated 3 times.

\section{Kinetics of struvite formation}

As struvite precipitates it releases hydrogen ions in solution causing a drop in $\mathrm{pH}$, directly linked to rate of struvite formation and to the consumption of magnesium ions reacting to form struvite. In the system studied here, struvite formed according to the following equation: 
From equation (i), the rate of struvite occurrence can then be expressed as:

$$
\frac{\mathrm{d}\left[\mathrm{MgNH}_{4} \mathrm{PO}_{4} \cdot 6 \mathrm{H}_{2} \mathrm{O}\right]}{\mathrm{dt}}=\frac{1}{2} \frac{\mathrm{d}\left[\mathrm{H}^{+}\right]}{\mathrm{dt}}=-\frac{\mathrm{d}\left[\mathrm{Mg}^{2+}\right]}{\mathrm{dt}}=-\frac{\mathrm{d}\left[\mathrm{NH}_{4}^{+}\right]}{\mathrm{dt}}=-\frac{\mathrm{d}\left[\mathrm{H}_{\mathrm{n}} \mathrm{PO}_{4}^{3-\mathrm{n}}\right]}{\mathrm{dt}}=\mathrm{Kr}
$$

where: $\mathrm{K}$ is the reaction kinetic constant and $\mathrm{r}$ is the rate of crystallisation in $\mathrm{mol} \mathrm{l}^{-1} \mathrm{~s}^{-1}$.

The rate of disappearance of $\mathrm{Mg}^{2+}\left(\mathrm{k}_{\mathrm{Mg}}\right)$ ions can then be defined as:

$$
-\frac{\mathrm{d}\left[\mathrm{Mg}^{2+}\right]}{\mathrm{dt}}=\mathrm{k}_{\mathrm{Mg}}\left[\mathrm{Mg}^{2+}\right] \text { or }-\frac{\mathrm{d}\left[\mathrm{Mg}^{2+}\right]}{\left[\mathrm{Mg}^{2+}\right]}=\mathrm{k}_{\mathrm{Mg}} \mathrm{dt}
$$

And the rate of appearance $\left(\mathrm{k}_{\mathrm{H}}\right)$ of $\mathrm{H}^{+}$ions is:

$$
\frac{1}{2} \frac{\mathrm{d}\left[\mathrm{H}^{+}\right]}{\mathrm{dt}}=\mathrm{k}_{\mathrm{H}}\left[\mathrm{H}^{+}\right] \text {or } \frac{1}{2} \frac{\mathrm{d}\left[\mathrm{H}^{+}\right]}{\left[\mathrm{H}^{+}\right]}=\mathrm{k}_{\mathrm{H}} \mathrm{dt}
$$

In the current work, mixing speed as well as $\mathrm{Mg}_{\mathrm{NH}}: \mathrm{PO}_{4}$ ratios were kept constant and the initial $\mathrm{pH}$ set to 9 to leave $\mathrm{Mg}$ as the main parameter influencing the precipitation rates of struvite. Consequently, the rate of disappearance of $\mathrm{Mg}^{2+}$ ions equalled the rate of appearance of $\mathrm{H}^{+}$, so combining equation (iii) and (iv) lead to the following expression

$$
-\frac{\mathrm{d}\left[\mathrm{Mg}^{2+}\right]}{\left[\mathrm{Mg}^{2+}\right]}=\frac{1}{2} \frac{\mathrm{d}\left[\mathrm{H}^{+}\right]}{\left[\mathrm{H}^{+}\right]}
$$

By integrating equation $(v)$ between the initial time $(t=0)$ and the final time $(t=25 \mathrm{~min}$ or $60 \mathrm{~min}$ at pilot scale), it was then possible to link the magnesium concentration to the $\mathrm{pH}$ value recorded over time as by definition $\mathrm{pH}=-\mathrm{Log}\left[\mathrm{H}^{+}\right]$as followed: 
$-\int_{0}^{\mathrm{t}} \frac{\mathrm{d}\left[\mathrm{Mg}^{2+}\right]}{\left[\mathrm{Mg}^{2+}\right]}=\frac{1}{2} \int_{0}^{\mathrm{t}} \frac{\mathrm{d}\left[\mathrm{H}^{+}\right]}{\left[\mathrm{H}^{+}\right]}$

$\operatorname{Ln}\left[\mathrm{Mg}^{2+}\right]^{\mathrm{t}}=\operatorname{Ln}\left[\mathrm{Mg}^{2+}\right]_{0}-\frac{1}{2} \operatorname{Ln}\left(\frac{\left[\mathrm{H}^{+}\right]^{\mathrm{t}}}{\left[\mathrm{H}^{+}\right]^{\mathrm{o}}}\right)$

$\operatorname{Ln}\left[\mathrm{Mg}^{2+}\right]^{\mathrm{t}}=\operatorname{Ln}\left[\mathrm{Mg}^{2+}\right]_{0}-\frac{1}{2} \operatorname{Ln}\left(\frac{10^{-\mathrm{pHt}}}{10^{-\mathrm{pHo}}}\right)$

$\left[\mathrm{Mg}^{2+}\right]^{\mathrm{t}}=\operatorname{Exp}\left(\operatorname{Ln}\left[\mathrm{Mg}^{2+}\right]_{0}-\frac{1}{2}\left(\frac{10^{-\mathrm{pH}_{\mathrm{t}}}}{10^{-\mathrm{pH}_{0}}}\right)\right)$

This expression was then used to estimate the evolution of magnesium concentration over time using the different $\mathrm{pH}$ values recorded during the various laboratory and pilot scale experiments. The kinetic constants of struvite formation were then assessed by fitting a first order kinetic model to the different sets of data, as according to previous studies struvite kinetics of reaction were found to follow this model $[9,15]$. For pilot scale tests only the concentrations calculated in the initial stage of reaction were used to fit the model to compare them to lab-scale experiments and ensure that the constant determined corresponded to precipitation kinetics. The linear form of the modified expression of a first-order kinetics model given by Nelson et al. [9] has been used here. The form of the rate expression is:

$\operatorname{Ln}\left(C-C_{e q}\right)=-k t+\operatorname{Ln}\left(c-C_{0}\right)$

where: $C$ is the concentration of the reactant concentration at a moment $t$, Ceq the reactant concentration at equilibrium, $\mathrm{C}_{0}$ the initial reactant concentration, and $\mathrm{k}$ the kinetic constant.

In the present study, if the rate of $\mathrm{Mg}^{2+}$ reaction follows this model, a plot of $\mathrm{Ln}\left([\mathrm{Mg}]-\left[\mathrm{Mg}_{\text {eq }}\right]\right)$ versus time should be linear with a slope of $-\mathrm{k}$. 


\section{RESULTS AND DISCUSSION}

\section{Induction time}

Initial experiments at both laboratory and pilot scale used changes in solution $\mathrm{pH}$ to indicate the start and rate of struvite precipitation, hence to determine induction time for different initial magnesium concentrations. The effects of varying the concentration of $\mathrm{Mg}$ ions in solution on struvite precipitation are shown in Figures $2 \mathrm{a}$ and $2 \mathrm{~b}$. The plots of tangents to $\mathrm{pH}$ curves obtained for both laboratory and pilot scale experiments illustrate that when the concentration in $\mathrm{Mg}$ ions increase, the rate at which the $\mathrm{pH}$ drops also increases, indicating a strong influence of the $\mathrm{Mg}$ dose on the reaction kinetics. In his study of struvite crystallisation kinetics, Nkansah [16] also concluded that rates at which struvite precipitation reached a steady state were closely linked to the concentration of solutions in $\mathrm{Mg}$ from which it was precipitated, with induction times decreasing from 150 to 15 seconds for respective Mg concentrations increasing from 2.337 to $5.827 \mathrm{mM}$ in molar ratios $\mathrm{Mg}: \mathrm{N}: \mathrm{P} 1: 2: 2$.

Determination of the period of time preceding the occurrence of first crystals at laboratory scale showed that an increase in initial magnesium concentration from $1.2 \mathrm{mM}$ to $2.3 \mathrm{mM}$ resulted in an approximately 10 fold reduction of the induction time (Table 1). These results are in accordance with previous studies that have demonstrated that the induction time for struvite crystallisation was mainly reaction controlled (i.e. $\mathrm{pH}$ and supersaturation dependant) [13]. For instance, Bouropoulos and Koutsoukos [11] also demonstrated the dependence of the induction time on solution supersaturation, hence $\mathrm{Mg}$ dose. For precipitation tests in synthetic solutions $\left(\mathrm{MgCl}_{2} .7 \mathrm{H}_{2} \mathrm{O}+\mathrm{NH}_{2} \mathrm{H}_{2} \mathrm{PO}_{4}\right)$ at $\mathrm{pH} 8.5$ they reported similar trends as for an increase of $\mathrm{Mg}$ from 
$2.75 \mathrm{mM}$ to $4 \mathrm{mM}$, the relative induction period decreased from $125 \mathrm{~min}$ to $6 \mathrm{~min}$. However, times taken for struvite crystals to occur in the present system are higher than that observed by Bouropoulos and Koutsoukos [11]. These variations can be attributed to the difference in $\mathrm{pH}$ of precipitation and conditions of precipitation (i.e. composition of synthetic solutions, mixing energy, temperature and agitation). Indeed Nelson et al. [9] illustrated the effects of $\mathrm{pH}$ on struvite precipitation rates in anaerobic swine lagoon effluents by showing that rate constants varied significantly from $3.7 \mathrm{~h}^{-1}$ to $12.3 \mathrm{~h}^{-1}$ between $\mathrm{pH} 8.4$ and 9.

At pilot scale, induction times were less affected by variations in magnesium concentrations than for laboratory tests (Table 1). For example, at the $\mathrm{Mg}$ concentration of $1.2 \mathrm{mM}$, the solution became cloudy after 12 minutes of reactor operation, while at $2.3 \mathrm{mM}$ the first particles were visible only 6 minutes after the filling up start.

From the previous observations it is clear that the intensity of the drop in $\mathrm{pH}$ is linked to the concentration in magnesium initially present in solution and is characteristic of the speed at which the first crystals of struvite occur, consequently to the rate of struvite formation. Finding a relationship between $\mathrm{pH}$ and $\mathrm{Mg}$ concentration against time could then help to predict kinetics of struvite precipitation and determine rate constants of struvite formation under specific condition of precipitation.

\section{Kinetics of precipitation}

Equation (vi) has been used to assess the evolution of the magnesium concentration versus time from the different $\mathrm{pH}$ measurements shown in Figures $2 \mathrm{a}$ and $2 \mathrm{~b}$. Based on the literature $[9,15]$, the struvite formation reaction has been assumed to obey a first-order kinetic model with respect to $\mathrm{Mg}$ and $\mathrm{H}$ ions. 
Figure 3 illustrates plots of $\mathrm{Ln}\left(\left[\mathrm{Mg}^{2+}\right]-\left[\mathrm{Mg}^{2+}\right]_{\mathrm{eq}}\right)$ versus time for the different experimental conditions tested at laboratory scale. The different plots revealed that calculated $\mathrm{Mg}$ concentrations fit well to a first kinetic order model, where correlation coefficients $\left(\mathrm{R}^{2}\right)$ ranged from 0.92 to 0.99 over the range of initial Mg concentrations tested.

At pilot scale, good correlations of the magnesium concentration calculated to the first-order kinetic model were also obtained with $\mathrm{R}^{2}$ values 0.92 to 0.98 over the range of initial $\mathrm{Mg}$ concentrations tested (i.e. $1.2 \mathrm{mM}, 1.64 \mathrm{mM}, 2.3 \mathrm{mM}$ and $3.5 \mathrm{mM}$ ). The rate constants obtained from each plot are reported in Table 2.

Kinetic constants seem to follow a trend in that the higher the initial $\mathrm{Mg}$ concentration, the higher the rate constant and so the faster the precipitation. To illustrate, kinetic constants obtained at laboratory scale ranged from 9.7 to $15.7 \mathrm{~h}^{-1}$ for $\mathrm{Mg}$ increasing from 1.2 to $3.5 \mathrm{mM}$, while at pilot scale kinetic constants ranged from 2.4 to $9.6 \mathrm{~h}^{-1}$ between 1.2 and $2.3 \mathrm{mM}$.

Comparison of the laboratory and the pilot tests for similar initial concentrations showed that rate constants at pilot scale were significantly lower than those determined at laboratory-scale, especially for low concentrations in $\mathrm{Mg}$. For an $\mathrm{Mg}$ concentration of $1.2 \mathrm{mM}$ at both laboratory and pilot scale, kinetic constants were respectively $9.2 \mathrm{~h}^{-1}$ and $2.4 \mathrm{~h}^{-1}$ while at a $\mathrm{Mg}$ concentration of $2.3 \mathrm{mM}$ kinetic constants were $13.4 \mathrm{~h}^{-1}$ and $9.6 \mathrm{~h}^{-1}$ (Table 2). Nelson et al. [9] reported for anaerobic swine lagoon that lower kinetics constants are influenced by the time taken for the crystallisation to start, or induction time. As induction times observed for precipitation tests in the reactor were significantly longer than at lab scale (Table 1), this would explain the lower rate constants determined at pilot scale. Furthermore, although previous studies have minimised the influence of mixing energy on struvite crytallisation kinetics [13], 
mixing energy in small volumes of solution such as in jar tests are thought to be higher than in the 101 reactor agitated with air, hence accelerating the kinetics of precipitation.

When compared to rate constants observed in the literature, the values obtained here are in the range of those reported for struvite precipitation in real liquors. For example, in their study of struvite kinetics using sludge lagoon supernatants in a pilot fluidised bed reactor, Ohlinger et al. [17] determined a rate constant of $4.2 \mathrm{~h}^{-1}$ at a precipitation $\mathrm{pH}$ of 8.3 , whereas Nelson et al. [9] found at laboratory scale a rate constant of $3.7 \mathrm{~h}^{-1}$ for struvite precipitated in similar media at $\mathrm{pH} 8.4$ and initial $\mathrm{Mg}$ concentrations varying from 0.8 to $1.2 \mathrm{mM}$. Constant rates determined by Nkansah [16] for identical conditions of precipitation as the one presented here (i.e. Mg:N:P molar ratio 1:2:2/ identical stock solutions, mixing apparatus and speed) were similar to the one calculated here at the same $\mathrm{Mg}$ concentrations. To illustrate, for initial Mg concentrations of 2.3 $\mathrm{mM}$ and $3.5 \mathrm{mM}$ the constant determined here were respectively of 13.4 and $15.7 \mathrm{~h}^{-1}$ while Nkansah [16] values were respectively of 11.3 and $13.3 \mathrm{~h}^{-1}$.

Furthermore, by applying equation (vi) used here to predict the evolution of $\mathrm{Mg}$ concentration with time to the set of $\mathrm{pH}$ data reported by Nkansah [16], the results confirmed the use of a first-order kinetics model to describe struvite precipitation kinetics and indicated an excellent correlation between the concentration calculated at equilibrium and actual concentrations in $\mathrm{Mg}$ measured at equilibrium by Inductively Coupled Plasma Emission Spectroscopy (Table 3). To illustrate, for an initial $\mathrm{Mg}$ concentration of $2.3 \mathrm{mM}$ the present model predicted an equilibrium concentration of $0.916 \mathrm{mM}$ while Nkansah [16] measured an equilibrium concentration of 0.922 $\mathrm{mM}$.

Although the kinetic model (i.e. first order model) observed in a scaled up reactor operated under similar chemical conditions of precipitation (Mg concentrations and associated Mg:N:P ratios) should be consistent with the one observed here, according to previous results a 
significant increase in the time taken for struvite precipitation to occur should result in even lower kinetic constants justified by the time taken in a larger reactor volume for the solutions to become homogenised [18]. A scaling up of the type of reactor described here would then imply even longer reaction time when using liquors with comparable characteristics. However the development of a design tool based on the kinetic rates found here which would also take into consideration reactor volumes and composition of liquors would then allow predicting for a specific reactor the parameters that need adjustment to optimise struvite precipitation rates for a given size of reactor.

Overall the understanding of struvite kinetics of crystallisation is the key to the development and the implementation of full scale struvite crystallisation reactors to be used as alternative solutions to technologies currently operated for the removal of phosphorus from sludge liquors. In biological processes such as EBPR systems, when sludges are treated by anaerobic digestion some polyphosphates can be released via hydrolysis and the phosphorus contained in liquors can lead to an increase of phosphorus being re-injected in the activated sludge process [19]. In that case, struvite crystallisation can be used as an additional step prior to the recycling of sludge liquors, hence allowing removal of a significant part of the phosphorus recycled back to the process and generating a recyclable by-product as already achieved in Japan [20] conversely to chemical precipitation of $\mathrm{P}$ with metal salts which produces $\mathrm{P}$ rich sludge that can not be recycled industrially [21].

\section{CONCLUSION}


The result presented here showed that $\mathrm{pH}$ measurement can be used for the prediction of the kinetics of struvite precipitation. The drop in $\mathrm{pH}$ typically observed during struvite precipitation reflects effectively rates at which struvite crystals nucleate. The magnesium concentration as expected has a major impact on struvite kinetics, with higher concentrations leading to shorter induction times, hence faster rates of precipitation leading to production of fine crystals. The present paper also showed that $\mathrm{pH}$ measurements correlated well with magnesium concentrations, especially at laboratory scale. However, investigations at both laboratory and pilot scale demonstrated that struvite precipitation in synthetic liquors corresponded to a first order kinetic model as observed in previous studies, confirming then the reliability of investigating kinetics from $\mathrm{pH}$ measurements.

\section{REFERENCES}

[1] UWWTD “Urban Waste Water Treatment Directive”, Council of the European communities, Council directive of 21 may 1991 concerning urban waste water treatment (91/271/EEC), Official Journal L, 135/40, (1991).

[2] Mulkerrins D., Dobson A.D.W. and Colleran E., Parameters affecting biological phosphate removal from wastewaters. Environ. Int., 30, 249-259, (2004)

[3] Parsons S.A. and Berry T.A., Chemical phosphorus removal. In: Phosphorus in Environmental Technologies, principles and applications, Valsami-Jones, E. (ed.), IWA publishing, pp. 260-272, (2004).

[4] Gaterell M.R., Gay R., Wilson R., Gochin R.J. and Lester J.N., An economic and environmental evaluation of the opportunities for substituting phosphorus recovered from wastewater treatment works in existing UK fertiliser markets. Environ. Technol., 21, 1067-1084, 
(2000).

[5] Johnston A.E. and Richards I.R., Effectiveness of different precipitated phosphates as phosphorus sources for plants. Soil Use Manage., 19, 45-49, (2003).

[6] Doyle J.D. and Parsons S.A., Struvite formation, control and recovery. Water Res., 36, 39253940, (2002).

[7] Ohlinger K.N., Young T.M. and Schroeder E.D., Predicting struvite formation in digestion. Water Res., 32, 3607-3614, (1998).

[8] Michalowski T. and Pietrzyk A., A thermodynamic study of struvite + water system. Talenta, 68, 594-601, (2006).

[9] Nelson N.O., Mikkelsen R.L. and Hesterberg D.L., Struvite precipitation in anaerobic swine lagoon liquid: effect of $\mathrm{pH}$ and $\mathrm{Mg}: \mathrm{P}$ ratio and determination of rate constant. Bioresource Technol., 89, 229-236, (2003).

[10] Jones A.G., Crystallization process system. Butterworth/ Heinemann, UK, (2002).

[11] Bouropoulos N.C. and Koutsoukos P.G., Spontaneous precipitation of struvite from aqueous solutions. J.Cryst.Growth, 213, 381-388, (2000).

[12] Kabdaşli I., Parsons S.A. and Tünay O., Effect of major ions on struvite crystallisation. In: Proceedings of the International Conference on Struvite: its role in phosphorus recovery and reuse, Cranfield (UK), (2004).

[13] Ohlinger K.N., Young T.M. and Schroeder E.D., Kinetics effects on preferential struvite accumulation in wastewater. J. Environ. Eng., 125, 730-737, (1999).

[14] Kabdaşli I., Parsons S.A. and Tünay O., Effect of major ions on induction time of struvite 
precipitation. Croat. Chem.Acta, 79, 243-251, (2006).

[15] Quintana M., Sanchez E., Colmenarejo M.F., Barrera J., Garcia G. and Borja R., Kinetics of phosphorus removal and struvite formation by the utilization of by-product of magnesium oxide production. Chem. Eng. Journal 111, 45-52, (2005).

[16] Nkansah D., Kinetics and mechanisms of struvite precipitation. MSc thesis, School of Water Sciences, Cranfield University, (UK), (2003).

[17] Ohlinger K.N., Young T.M. and Schroeder E.D., Post digestion struvite precipitation using a fluidised bed reactor, J. Environ. Eng., 126, 361-368, (2000).

[18] Nauman E. B., Chemical Reactor Design, Optimization, and Scale-up. McGraw-Hill, USA (2002).

[19] Oehmen A., Lemos P.C., Carvalho G., Yuan A., Keller J., Blackall L.L. and Reis M.A.M, Advances in enhanced bilogical phosphorus removal: from micro to macro scale, Wat. Res., 41, 2271-2300, (2007).

[20] Ueno Y. and Fujii M., Three years experience of operating and selling struvite from full scale plant, Environ. Technol., 22, 1373-1381, (2001)

[21] de-Bashan L.E. and Bashan Y., Recent advances in removing phosphorus from wastewater and its use as fertilizer (1997-2003), Wat. Res., 38, 4222-4246, (2004). 


\section{List of Figures}

Figure 1. Pilot scale unit

Figure 2. Average $\mathrm{pH}$ versus time for various initial magnesium concentrations at lab-scale (a) and pilot scale (b). (Deviation of $\mathrm{pH}$ measurement $\leq 0.05$ for all experiments (a) and $(b))$.

Figure 3. Fit of calculated $\mathrm{Mg}^{2+}$ concentrations to the linear form of the first-order kinetic model.

\section{List of Tables}

Table 1. Struvite induction time at bench and pilot scale

Table 2. Rate constants calculated for struvite solutions of various initial $\mathrm{Mg}$ concentrations

Table 3. Comparison between equilibrium concentrations measured by Nkansah [16], and the corresponding concentrations predicted. 
Table 1. Struvite induction time at bench and pilot scale

\begin{tabular}{|c|c|c|c|c|}
\hline & \multicolumn{2}{|c|}{$\begin{array}{l}\text { Induction time in } \\
\text { beakers } \\
(\mathrm{min})\end{array}$} & \multicolumn{2}{|c|}{$\begin{array}{l}\text { Induction times in } \\
\text { reactor } \\
\text { (min) }\end{array}$} \\
\hline & Eye visible & $\begin{array}{c}\text { Estimated } \\
\text { from pH } \\
\text { graphs }\end{array}$ & Eye visible & $\begin{array}{c}\text { Estimated } \\
\text { from pH } \\
\text { graphs }\end{array}$ \\
\hline $1.20 \mathrm{mM}$ & 5 & 5 & 12 & 12 \\
\hline $1.64 \mathrm{mM}$ & 2 & 1.8 & 6.8 & 7 \\
\hline $1.96 \mathrm{mM}$ & $<1$ & 0.8 & 6.7 & 7 \\
\hline $2.30 \mathrm{mM}$ & $<0.5$ & $<0.5$ & 6 & 6 \\
\hline
\end{tabular}


Table 2. Rate constants calculated for struvite solutions of various initial $\mathrm{Mg}$ concentrations

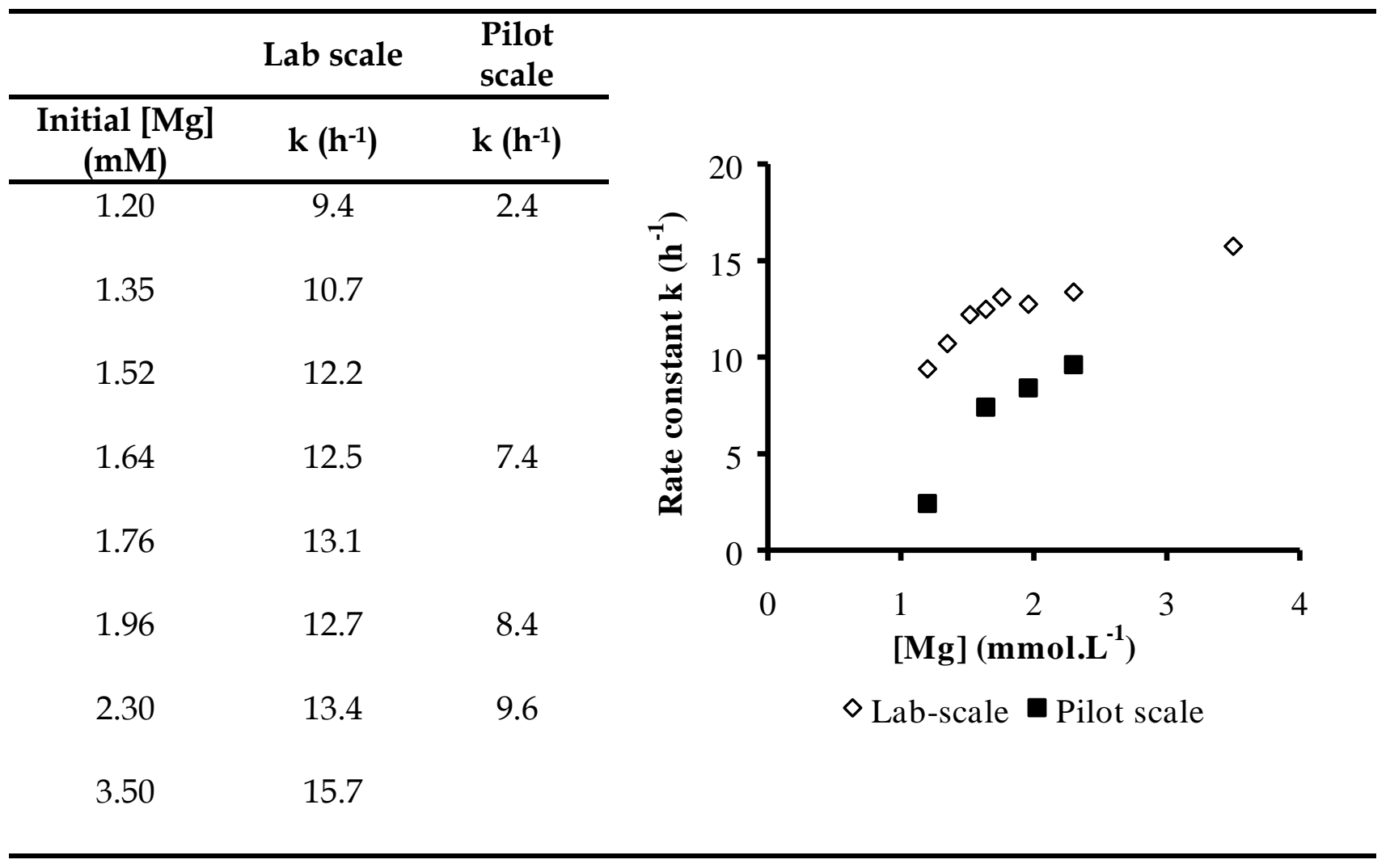


Table 3. Comparison between equilibrium concentrations measured by Nkansah [16], and the corresponding concentrations predicted.

\begin{tabular}{cccc}
\hline & Nkansah [16] & \multicolumn{2}{c}{ Current work } \\
\hline $\begin{array}{c}\text { Initial }[\mathrm{Mg}] \\
(\mathrm{mM})\end{array}$ & $\begin{array}{c}\text { Measured }[\mathrm{Mg}] \text { at equilibrium } \\
\text { (ICP analyses/ mM) }\end{array}$ & $\begin{array}{c}\text { [Mg] calculated } \\
\text { with the current } \\
\text { model (equation7) }\end{array}$ & Error (\%) \\
1.2 & 0.666 & 0.683 & 2.5 \\
2.3 & 0.922 & 0.916 & 0.7 \\
3.5 & 1.010 & 1.009 & 0.1 \\
\hline
\end{tabular}

